\section{SAT0121 ORAL MORPHINE VERSUS ORAL HYDROMORPHONE IN RHEUMATOLOGIC NON-MALIGNANT PAIN: A PROSPECTIVE RANDOMISED STUDY IN 144 PATIENTS}

R Grilo, C Scoto Di Fazano, D Coyral, P Bertin, C Bonnet, R Treves. Rheumatology, CHU Dupuytren, Limoges, France

\subsection{6/annrheumdis-2001.554}

Background Morphine and hydromorphone are commonly used as opioids in cancer pain. The management of non-malignant pain is sometime difficult. A recent and debated therapeutic consideration is the used of morphine in intractable Rheumatologic Non-Malignant Pain (RNMP).

Objectives The purpose of this prospective randomised study was to compare the efficacy of pain relief and side effects of oral hydromorphone and oral morphine in RNMP.

Methods 144 patients suffering from RNMP were assigned to receive oral morphine or oral hydromorphone. Different criteria were affeffed: dose of morphine ( $\mathrm{mg} /$ day), duration of treatment (days), baseline and post-treatment evaluation of pain using a Visual Analogic Scale (VAS, in $\mathrm{cm}$ ). The prevalence of nausea was assessed in the two groups.

Results

\begin{tabular}{llllll}
\multicolumn{1}{l}{ Abstract SAT0121 Table 1 } & & & \\
\hline & $\begin{array}{l}\text { Mean } \\
\text { age } \\
\text { (years) }\end{array}$ & $\begin{array}{l}\text { Mean } \\
\text { duration } \\
\text { (days) }\end{array}$ & $\begin{array}{l}\text { Mean } \\
\text { dose } \\
\text { (mg/ } \\
\text { day) }\end{array}$ & $\begin{array}{l}\text { VAS } \\
(\mathrm{Cm})\end{array}$ & $\begin{array}{l}\text { Number of patients with } \\
\text { nausea }\end{array}$ \\
\hline $\begin{array}{l}\text { Oral } \\
\text { hydromorphone }\end{array}$ & 56 & 8.1 & 10.8 & 3.7 & 16 \\
$\begin{array}{l}\text { Oral morphine } \\
\text { p }\end{array}$ & 52.7 & 7.8 & 67.7 & 4 & 20 \\
\hline
\end{tabular}

Conclusion We observed a VAS mean decrease of $3.7 \mathrm{~cm}$ with oral hydromorphone and $4 \mathrm{~cm}$ with oral morphine, despite oral hydromorphone provides no statistical significant benefit over oral morphine in RMNP.

\section{SAT0122 OPIOID ROTATION WITH ORAL MORPHINE TO ORAL HYDROMORPHONE IN RHEUMATOLOGIC NON CANCER PAIN: A RETROSPECTIVE STUDY}

R Grilo, C Scotto Di Fazano, D Coyral, P Bertin, C Bonnet, R Treves. Department of Rheumatology, CHU Dupuytren, Limoges, France

10.1136/annrheumdis-2001.555

Background Although being a controversal debated, opioids may be an alternative therapeutic in intractable rheumatologic nonmalignant pain (RNMP). Different mecanisms including receptor activity, cross over tolerance and toxic metabolits can explaine the differences in analgesic or adverse effect responses among opioids.

Objectives To determinated that rotation with oral morphine to oral hydromorphone can be useful for establishing a more advantages analgesia/toxicity relationship.

Methods We made retrospectivly 24 rotations in patients suffering from RNMP. Different criteria were assessed: dose of morphine and hydromorphone $(\mathrm{mg} /$ day), duration of treatment (days), evaluation of pain using a Visual Analogic Scale (VAS, $\mathrm{cm}$ ) before and after rotation, and finally the causes of rotation. Results 11 rotations were made for nausea and 13 for inefficacity. There is a significant statistical decrease of VAS after rotation (test of Student).

\begin{tabular}{|c|c|c|c|}
\hline & $\begin{array}{l}\text { Oral morphine } \\
\text { (mg/day) }\end{array}$ & $\begin{array}{l}\text { Oral hydromorphone } \\
\text { (mg/day) }\end{array}$ & $\begin{array}{l}\text { Decrease VAS } \\
(\mathrm{cm})\end{array}$ \\
\hline Mean & 63.5 & 11.7 & 3.87 \\
\hline Standard deviation & 13.7 & 3.5 & 2.1 \\
\hline
\end{tabular}

Conclusion Oral hydromorphone appeared to result in improvement of pain relief after rotation, and may provide a suitable alternative to bypass nausea. We observed an average morphine/ hydromorphone ratio of $7: 1$, which has become the accepted standard.

\section{SAT0123 THE EFFICACY OF ROFECOXIB IN THE TREATMENT OF INFLAMMATORY ARTHROPATHIES}

'MS Capraru, ${ }^{2} E$ Ilie. 'Rheumatology Service, "Prof. Dr. D. Gerota" Military Hospital, Bucharest, Romania; ${ }^{2}$ Rheumatology Service, Military Center for Diagnostic and Treatment, Bucharest, Romania

\subsection{6/annrheumdis-2001.556}

Background The research aimed the development of a prospective investigation on the efficacy of the rofecoxib treatment in inflammatory arthropathies patients.

Our previous expertize enabled us to suspect that there might be some consistent effects of the rofecoxib of the inflammatory disease class.

Objectives Consequently the main objective of our research was to point out the influences of rofecoxib as an alternative treatment in the inflammatory disease class.

Methods Basically, the method consists of taking measurements and surveying the effects of the rofecoxib treatment on patients during a two week time interval.

The study involved a 55 patients target group with the following structure: acute gout present at 15 of them, 19 patients had seronegative spondylarthropathies, 7 suffering of psoriatic arthritis, 10 of them presenting rheumatoid arthritis and 2 patients diagnosticated as systemic sclerosis associated arthritis.

The survey assumed the pain score measurement in terms of an analogical pain scale from 0 (no pain) to 10 (very severe pain). The measurements were taken at $48 \mathrm{~h}, 72 \mathrm{~h}, 7$ days and 14 days following the initial moment when the therapy with rofecoxib started.

Results Our results can be summarised as follows: very high efficacy in acute gout (50 $\mathrm{mg}$ in the first day, then $25 \mathrm{mg} / \mathrm{day})$ together with significant decrease of the $48 \mathrm{~h}$ pain score. Also, good efficacy can be reported in case of seronegative spondylarthropathies, psoriatic arthritis and systemic sclerosis associated arthritis $(25 \mathrm{mg} /$ day 7 days, followed by $12.5 \mathrm{mg} /$ day) but for patients suffering of rheumatoid arthritis the efficacy can be considered as being almost satisfactory $(25 \mathrm{mg} /$ day). However, the investigation of the chronic arthropathies patients continued for about two more months, and no digestive, hepatic or renal adverse reactions were reported while the whole therapeutic benefit was preserved. 
Conclusion We can conclude on this basis that the results confirmed most of our expectations but the experiment allowed us to refine our a priori hypothesis.

\section{SAT0124 COMPARATIVE SAFETY AND EFFICACY OF TRANSDERMAL FENTANYL (DUROGESIC ${ }^{\circledR}$ ) AND SUSTAINED-RELEASE ORAL MORPHINE (MS CONTIN ${ }^{\circledR}$ ) IN PATIENTS WITH CHRONIC NON-CANCER PAIN: RESULTS OF A LARGE, MULTICENTER, RANDOMISED, CROSSOVER TRIAL}

${ }^{1}$ L Allan, ${ }^{2}$ E Kalso. ${ }^{1}$ The Pain Clinic, Northwick Park and St Mark's NHS Trust, Harrow, UK; ${ }^{2}$ Helsinki University, Central Hospital Pain Clinic, Helsinki, Finland

\subsection{6/annrheumdis-2001.557}

Background Opioids are the most powerful analgesics, but politics, prejudice and continuing ignorance still impede optimum prescribing. ${ }^{1}$ Furthermore, opioids are the mainstay of cancer pain management. Retrospective and survey data have confirmed the efficacy of opioids in chronic non-cancer pain (CNCP) and found that fears of addiction were not justified in patients with no prior history of drug abuse. ${ }^{2}$ While morphine, usually prescribed orally in a sustained-release formulation for the treatment of CNCP, is the standard opioid against which others are judged, severe constipation (a persistent complication of some opioids) may adversely affect some patients? quality-of-life more than their chronic pain. ${ }^{3}$ Fentanyl, delivered in a transdermal controlled-release formulation, has demonstrated analgesic efficacy in cancer pain and is associated with less constipation than morphine. ${ }^{4}$ Recognising the increasing importance of patient preference and choice, the authors investigated whether CNCP patients accustomed to opioids would prefer transdermal fentanyl (TDF) to sustained-release oral morphine (SRM).

Objectives

Methods A randomised, multicenter, international, open-label crossover trial assessed 8 weeks of TDF and SRM therapy. Patients previously treated with opioids with CNCP, were randomised to receive TDF and then SRM, each for 4 weeks, or the same treatments in reverse order.

Results Of the 256 patients entering the study 196 completed the trial, with 38 and 22 patients withdrawing during the TDF $(\mathrm{n}=126)$ and SRM $(\mathrm{n}=130)$ treatment periods, respectively. Most patients (65.1\%) preferred TDF ( $\mathrm{p}<0.001$ ), 27.8\% preferred SRM and 7.1\% expressed no preference. More patients considered that pain control was ?good? or ?very good? with TDF than with SRM (35\% vs $23 \%, \mathrm{p}=0.002)$. Patients using TDF had, on average, higher quality-of-life scores than those receiving SRM. The incidence of adverse events was similar in both treatment groups; however, more subjects experienced constipation when treated with SRM than with TDF (48\% vs $29 \%$, respectively; $p<0.001)$. More patients withdrew because of adverse events during the TDF than in the SRM treatment periods (10\% vs $5 \%$, respectively). However, within a subgroup of 66 patients that had used neither fentanyl nor morphine prior to the study (they had used other opioids), similar numbers withdrew due to adverse effects during TDF and SRM treatments (11\% vs $10 \%$, respectively).

Conclusion Both TDF and SRM treatments were well tolerated, with good safety profiles in patients with CNCP who had previously been treated with opioids. Superior pain relief and less constipation were associated with TDF compared with SRM therapy.

\section{REFERENCES}

1 McQuay H. Lancet 1999;353:2229-32

2 Portenoy RK. J Pain Symptom Manage. 1996;11:203-17

3 Cummings-Ajemian I. In: Patt RB, ed. Cancer pain. Philadelphia: JB Lippencott Company, 1993

4 Ahmedzai S, Brooks D. J Pain Symptom Manage. 1997;13:254-61

\section{SAT0125 TRANSDERMAL FENTANYL (DUROGESIC ${ }^{\circledR}$ ) PRODUCES STABLE ANALGESIA AND IMPROVED QUALITY OF LIFE IN PATIENTS WITH CHRONIC NON-CANCER PAIN. THE RESULTS OF A 12-MONTH STUDY}

K Milligan. Department of Anaesthesia, South Cleveland Hospital, Middlesbrough, UK

\subsection{6/annrheumdis-2001.558}

Background Persistent and misplaced fears about the risks of tolerance, physical dependence and addiction have led to the underuse of opioids for the treatment of chronic non-cancer pain (CNCP). Opioids are widely used for the alleviation of acute pain and cancer pain, and are established as the second and third steps of the World Health Organisation analgesic ladder. Evidence suggests, however, that pain is frequently undertreated even for these indications. ${ }^{1}$ Nevertheless, several shortterm, randomised controlled trials have shown that opioids can be used successfully to treat CNCP without causing undue adverse events. ${ }^{2-4}$ A previous randomised crossover trial demonstrated that, over a 2-month period, 256 patients with $\mathrm{CNCP}$ preferred transdermal fentanyl (TDF) to sustained-release oral morphine due to better pain control, less constipation and some improvements in quality-of-life parameters. ${ }^{5}$ Although these short-term data are encouraging, no prospective trials have assessed the long-term efficacy and safety of opioid analgesia in CNCP.

Objectives The objectives of this international, multicenter, open-label trial were to assess the efficacy and safety of up to 12 months? therapy with TDF in patients with CNCP.

Methods The efficacy and safety of up to 12 months? therapy with TDF was assessed in patients with CNCP who required continuous opioid analgesia. Patients? opioid preference (compared with their previous analgesic), pain control and quality of life were evaluated. TDF therapy was initiated at an equianalgesic dose to pre-trial opioids, then titrated to maintain acceptable pain control and side-effects.

Results Of the 532 patients recruited, 301 (57\%) completed the full 12-month trial. A total of 530 patients were included in the safety analysis and 524 in the efficacy analysis. During the study 130 patients $(25 \%)$ from the efficacy group withdrew because of adverse events and 39 (7\%) due to insufficient analgesia. Weekly assessments indicated that the percentage of patients who perceived pain control as very good, good or moderate remained stable over 12 months, at an average of $67 \%$, with $47 \%$ citing better analgesia and $27 \%$ convenience as the main reason. Global treatment satisfaction also remained stable, with $42 \%$ reporting very good or good pain control. Medical Outcomes Study (MOS) and Short Form 36 (SF-36) quality-of-life measures showed improvements after 12 months? treatment compared with baseline. The most common adverse events were nausea, somnolence, constipation, vomiting and increased sweating. One of the nine deaths during the trial was considered possibly related to TDF treatment (severe bronchopneumonia). No problems of opioid withdrawal symptoms or addiction were encountered. 